\title{
Management of Neonatal Seizures - A Focus on Neuropharmacological Aspects
}

\author{
Dias $\mathrm{E}^{1 *}$, Mithun $\mathrm{S}^{2}$ and Varghese GS1 \\ ${ }^{1}$ Dept of Pediatrics, SIMS \& RC, India \\ ${ }^{2}$ Dept of Psychiatry, SIMS \& RC, India
}

*Corresponding author: Edwin Dias, Professor \&HOD, Dept of Pediatrics, SIMS\&RC,

Review Article
Volume 3 Issue 4
Received Date: December 13, 2018
Published Date: December 26, 2018

Adjunct Professor, Srinivas University, India, Emil: dredwindias@gmail.com

\begin{abstract}
Neonatal seizures can cause significant morbidity and even mortality in neonates. The prompt identification referral evaluation, treatment and follow up are essential for improving prognosis. The different anti-epileptic drugs like Phenobarbitone, Levetiracetam have advantages and disadvantages especially neuropharmacological and also in the treatment of neonatal seizures. The aim of this review is to give an overview of the clinical utility of various drugs which are used in the management of neonatal seizures.

Keywords: Neonatal seizures; Anti- epileptic drugs (AED); Central nervous system (CNS)
\end{abstract}

Abbreviations: LFT: Liver Function Tests; CSF: Cerebrospinal Fluid; EEG: Electroencephalography; AED: Anti- Epileptic Drugs; CNS: Central nervous system; GABA: Gamma Aminobutyric Acid; ILAE: International League Against Epilepsy; HIE: Hypoxic-Ischemic Encephalopathy; NS: Normal Saline; NCSE: Non Convulsive Status Epilepticus.

\section{Introduction}

Seizures are one of the commonest manifestations of neurological dysfunction in children. Seizures in neonates are abnormal paroxysmal hyper-synchronous neuronal discharge in the brain (motor and autonomic function). Neonatal seizures have an incidence of $2.8 / 1000$ in infants having birth weight $>2500 \mathrm{~g}$ and about 57.5/1000 in infants of very low birth weight. Neonatal seizures put the newborns at risk for neurologic impairment like developmental delay and post-neonatal epilepsy. Though, neonatal seizure associated mortality has reduced from
$40 \%$ to $20 \%$, prevalence of long-standing neurodevelopmental sequelae is almost the same at $30 \%$ $[1,2]$.

\section{Objectives}

1) Review of the literature on diagnosis and etiological classification of neonatal seizures.

2) Neuropharmacological aspects of drugs involved in the management of newborn convulsion.

\section{Methods}

We employed the Google scholar and PubMed search engine looking for phrases like 'neonatal seizures', 'pharmacology of neonatal seizures, anti-epileptics in neonatal seizures' etc. Relevant literature in the form of review articles, case reports, books, etc were reviewed. We would like to acknowledge all the authors of the articles reviewed from which information has been included. 


\section{Pediatrics \& Neonatal Biology Open Access}

\section{Classification of Neonatal Seizures}

In the previous 1981 classification of neonatal seizures were considered as a separate entity but in the 2005-2009 report of International League Against Epilepsy (ILAE) commission on classification itis no longer considered as a separate entity [3]. But for the purpose of easy understanding neonatal seizures can be divided into the following types:

a. Subtle (Preterm and Term): Eye deviation (Term), Blinking, fixed stare (Preterm), Repetitive buccal movements, Apnea, Pedaling, tonic posturing of limbs.

b. Tonic (Primarily Preterm): Focal or generalized, Tonic limb extension or flexion (suggesting severe Intracranial Hemorrhage in preterm infants)

c. Clonic (Primarily term): May be focal/multifocal, Clonic limb movements (which can be synchronous or asynchronous, can be localized without any anatomic order in progression) When consciousness is preserved, often it suggests localized cerebral injury.

d. Myoclonic (Rare): Focal, Multifocal, or Generalized, Lightning-like jerks in extremities (upper>lower) [4,5].

\section{Etiology of Neonatal Seizures}

The common causes in neonates are hypoxic-ischemic encephalopathy (HIE), metabolic disturbances, intracranial hemorrhage, stroke, infection and other etiologies. In a 4-year retrospective chart review study, HIE amounted to $36.4 \%$, infections about $19.1 \%$, metabolic disorders $7.3 \%$, structural disorders $1.8 \%$ in etiology of neonatal seizure. The commonest type was subtle followed by myoclonic, type of neonatal seizures [6].

\section{Diagnosis: Includes Investigations}

A rapid diagnosis and prompt treatment are needed for neonatal seizures as delay may result in poor prognosis. Preliminary assessment of seizures in neonates should focus on prompt identification of the probable causes with basic evaluation of metabolic and infection profile parameters [6]. The newborn's history and brief preliminary clinical examination and blood collection should be carried out ideally within 2-5 min. Investigation profile in neonates with NS include blood examination like sugars, serum electrolytes $\left(\mathrm{Na}^{+}, \mathrm{K}^{+}, \mathrm{Cl}-\right)$, calcium, magnesium, hematocrit, liver function tests (LFT's), arterial blood gas, CSF(cerebrospinal fluid) examination, electroencephalography (EEG), CT\&MRI scanning, TORCH screen for congenital infections [6].

\section{Management}

Initial management: A holistic management of neonatal seizures will ensure adequate circulation, airway, breathing and thermostat is of patient. The emergency management in neonatal seizures will be to ensure the adequacy of circulation, airway, and breathing and adequate thermoneutral environment of the patient. The requirement of oxygen should be assessed in preterm and then the correct $\mathrm{FiO}_{2}$ is administered and IV access secured followed by withdrawing blood sample for investigations. If blood sugar is low immediately $2 \mathrm{ml} / \mathrm{kg}$ of $10 \%$ dextrose should be administered as a bolus followed by $6-8 \mathrm{mg} / \mathrm{kg} / \mathrm{min}$ infusion. If the convulsion persists the child has to receive IV $10 \%$ calcium gluconate at $2 \mathrm{ml} / \mathrm{kg}$ over $10 \mathrm{~min}$ with cardiac monitoring and in cases of hypocalcemia (low levels of ionized $\mathrm{Ca}^{++}$) should receive $8 \mathrm{ml} / \mathrm{kg} /$ day for 3 days. If the seizure continues after correcting $\mathrm{Ca}^{++}$, Magnesium sulphate should be given IM at $0.25 \mathrm{ml} / \mathrm{kg}$ of $50 \%$ Magnesium [1].

\section{Pharmacological Approach}

A good history is most important for the diagnosis and treatment of seizure, along with observation and clinical evaluation. The goal of the treatment is complete control of seizures without any significant side effects. Antiepileptic Drugs (AED's) are given when seizures persist despite correction of low blood sugars and calcium levels. Drugs are initiated with low doses then gradually optimized to adequate doses in therapeutic and prophylactic treatments. If seizure control is not obtained with adequate doses of first line agents, then options of optimization, switching to second/third line agents, augmentation strategies are sought out. In therapeutic and prophylactic phases of treatment systematic monitoring is important as side effects with AED's are commonly seen. In most of the cases AED's can be withdrawn after 2 years of seizure free duration [8].

\section{First Line and Second Line Agents}

Phenobarbitone: Phenobarbital is an effective antiepileptic drug. It is a long-acting barbiturate. It is an agonist at gamma aminobutyric acid (GABA) receptors in the CNS which is the primary inhibitory neurotransmitter in the central nervous system (CNS), thus suppressing seizure activity. Phenobarbital is a safe drug but with few serious adverse effects. Phenobarbital monotherapy controls seizures in $43 \%$ to $85 \%$ of the affected neonates.

Phenobarbital administered by mouth is slowly absorbed, and intramuscular absorption takes 2 to 4 hours, the drug must be given intravenously to have a rapid response in infants, the loading dose is IV $20 \mathrm{mg} / \mathrm{kg}$ and maintenance dose is 3 to $4 \mathrm{mg} / \mathrm{kg}$ per oral per day. If seizure persists additional bolus doses of 5 to $10 \mathrm{mg} / \mathrm{kg}$ (maximum $40 \mathrm{mg} / \mathrm{kg}$ ) Phenobarbital given until seizures subside. The optimal serum concentration of 


\section{Pediatrics \& Neonatal Biology Open Access}

Phenobarbital is $40 \mu \mathrm{g} / \mathrm{ml}$. The suggested Phenobarbital loading dose for neonates with hypoxic-ischemic seizures is $20 \mathrm{mg} / \mathrm{kg}$. Infants with refractory seizures receive additional dosage to a maximum serum concentration of $100 \mu \mathrm{g} / \mathrm{ml}$. Since adverse effects are dose dependent Phenobarbital concentrations above $40 \mu \mathrm{g} / \mathrm{ml}$ cause sedation thus causing feeding difficulties and above 60 $\mu \mathrm{g} / \mathrm{ml}$ may cause respiratory depression [9-14].

Phenytoin and Fosphenytoin: Phenytoin is one of the second line agents due to its unique properties. Phenytoin (Fosphenytoin) is ideally recommended in acute treatment and not for long-term. The mechanism of action of Phenytoin is in modulating $\mathrm{Na}+$ channels in the cortex thus stabilizing the neurons either during the production of neuronal impulses.

Phenytoin is used as $2^{\text {nd }}$ line when optimal dose of Phenobarbitone $(40 \mathrm{mg} / \mathrm{kg})$ doesn't control the seizures or due to the intolerable adverse effects of phenobarbitone respiratory depression, hypotension or bradycardia. The recommended dosage of Phenytoin is $15-20 \mathrm{mg} / \mathrm{kg}$ IV (or the equivalent active dose of phosphenytoin) with cardiac monitoring and shouldn't exceed $1 \mathrm{mg} / \mathrm{kg} / \mathrm{min}$. A second dose of $10 \mathrm{mg} / \mathrm{kg}$ may be required in cases of refractory seizures. The maintenance dose is $3-5 \mathrm{mg} / \mathrm{kg} / \mathrm{d}$ (up to $8 \mathrm{mg} / \mathrm{kg} / \mathrm{d}$ ) given in $2-4$ divided doses. Phenytoin has to be diluted with normal saline (NS) because of its incompatibility with dextrose solution. Maximum therapeutic serum levels are around $10-20 \mu \mathrm{g} / \mathrm{ml}$, beyond which toxicity may occur. Since oral suspension can have erratic gut absorption, IV is the preferred route in neonates. Fosphenytoin is a watersoluble prodrug of Phenytoin when given IV does not cause the same degree of hypotension or cardiac abnormalities in comparison to Phenytoin and when given IM) is less likely to result in soft-tissue injury. Dosage of Fosphenytoin is expressed in Phenytoin equivalents $(1.5 \mathrm{mg} / \mathrm{kg}$ of Fosphenytoin is equivalent to 1 $\mathrm{mg} / \mathrm{kg}$ of Phenytoin).

The combination of Fosphenytoin and Phenytoin are shown to be effective in neonatal seizures; however, a poor side effect profile and narrow therapeutic index thus making it a less desirable choice. This combination has the adverse effects of hypotension and CNS depression thus requiring close therapeutic drug monitoring due to its nonlinear pharmacokinetics and a narrow therapeutic index. These pose a serious concern because when medications which have narrow therapeutic index and nonlinear pharmacokinetics increase the risk of toxicities as the range between efficacy and toxicity is very narrow and the drug level causing toxicity may be unknown as it can differ from patient to patient $[1,9,10,14,15]$.
Levetiracetam: The exact mechanism of action of Levetiracetam is unknown however some of its actions include inhibiting calcium channels, facilitating GAB Anergic inhibitory transmission via displacement of negative modulators, reducing or delaying potassium current, and binding to synaptic proteins that modulate neurotransmitter release.

Levetiracetam appears an effective; a well-tolerated and did not require adjunctive therapy for control of neonatal seizure in newborns. Levetiracetam is a substitute to Phenobarbitone of neonatal seizure associated with hypoxic ischemic encephalopathy (HIE). Usually the effective dose of Levetiracetam is between 20 $60 \mathrm{mg} \mathrm{kg} \mathrm{/} \mathrm{day.} \mathrm{It} \mathrm{can} \mathrm{be} \mathrm{started} \mathrm{at} 20 \mathrm{mg} / \mathrm{kg}$ in two divided doses and then increased every 1-2 weeks upto60 $\mathrm{mg} / \mathrm{kg} /$ day. Seizure control was achieved within one hour in about $86 \%$ of neonates who had taken Levetiracetam. Levetiracetam can be given IV as a loading dose of 20-50 $\mathrm{mg} / \mathrm{kg}$, followed by a maintenance dose of $5 \mathrm{mg} / \mathrm{kg}$, which may be increased if required. This drug is very commonly used both for acute and chronic management of neonatal seizure due to its tolerable side-effect profile, lack of drugto-drug interactions and large therapeutic index. The side effects are usually minor which lethargy, feeding difficulty, and mild hypertransaminasemia is usually can resolved with adjusting dose. On adjusting the doses of Levetiracetam these side effects tend to resolve [8$10,12,16,17]$.

Benzodiazepines (BZD): Benzodiazepines are utilized in seizure cases which are refractory to Phenobarbital (and/or Phenytoin, when seizure fails to respond to optimal doses of two AEDs. This group of drugs may be required in about $15-20 \%$ of neonates with seizure. Commonly used BZD's are Lorazepam and midazolam whereas diazepam is generally avoided in neonates due to its narrow therapeutic index, and presence of sodium benzoate as a preservative.

Lorazepam has a relatively longer half-life than Midazolam thus administration is less frequent with dosing being intermittent. This makes Lorazepam the most preferred Benzodiazepine in most of neonatal seizure cases. As Midazolam is short-acting and has a quick onset of action, hence commonly administered as an infusion. Whenever Midazolam infusion is used, careful monitoring for side effects like CNS and respiratory suppression, bradycardia etc. (lesser in comparison to Lorazepam) has to be done. All emergency resuscitation and ventilation equipment's need to be kept ready in cases of such adverse reactions 18. 


\section{Pediatrics \& Neonatal Biology Open Access}

Yet another BZD is Clonazepam which has been used in newborns who are doing not respond to Phenobarbitone and Phenytoin.

The loading doses of some BZD's are as follows:

- Lorazepam- 0.05-0.15 mg/kg in 5 minutes without maintenance doses (sometimes loading dose may be repeated)

- Midazolam-0.05-0.2 mg/kg in 10 minutes, following which further dosing of $0.1-0.5 \mathrm{mg} / \mathrm{kg} /$ hour (maximum $1.0 \mathrm{mg} / \mathrm{kg} / \mathrm{hour}$ ) may be required in ascending doses while monitoring for side effects.

- Clonazepam-0.1 mg/kg bolus, followed by $0.01 \mathrm{mg} / \mathrm{kg}$ which can be used up to five times in 24 hours although not widely used.

To antiepileptic drugs the response of newborn seizures to anticonvulsants is as follows, $40 \%$ to the 20 $\mathrm{mg} / \mathrm{kg}$ loading dose of Phenobarbitone, $70 \%$ to a total of $40 \mathrm{mg} / \mathrm{kg}$ of Phenobarbitone, $85 \%$ to a $20-\mathrm{mg} / \mathrm{kg}$ Phenytoin, and $95 \%$ to $100 \%$ to 0.05 to $0.1 \mathrm{mg} / \mathrm{kg}$ Lorazepam $[1,9,10,18]$.

Lidocaine: Lidocaine is an antiarrhythmic agent which acts in CNS by blocking the initiation as well as conduction of neuronal membranes permeability to sodium ions thus leading to inhibition of depolarization with the finally resulting in blockade of seizure activity. It is commonly administered in the form of a bolus dose of 4 $\mathrm{mg} / \mathrm{kg}$ IV then an infusion is given at the rate of 2 $\mathrm{mg} / \mathrm{kg} / \mathrm{hr}$ gradually it is tapered and decreased over several days [15]. For refractory seizures along with Benzodiazepines in term neonates being treated for hypothermia, the initial bolus loading dose of $2.0 \mathrm{mg} / \mathrm{kg}$ is given after which continuous infusions of $7 \mathrm{mg} / \mathrm{kg} / \mathrm{hour}$ for 3.5 hours, $3.5 \mathrm{mg} / \mathrm{kg} /$ hours for 12 hours, and 1.75 $\mathrm{mg} / \mathrm{kg} /$ hour for 12 hours, then stopping.

In normothermic infant's regimen gets altered where in: $2.0 \mathrm{mg} / \mathrm{kg}$ in 10 minutes, then followed by infusions of $7.0 \mathrm{mg} / \mathrm{kg} /$ hour during next 4 hours, and $3.5 \mathrm{mg} / \mathrm{kg} / \mathrm{hour}$ during next 12 hours, followed by $1.75 \mathrm{mg} / \mathrm{kg} /$ hour in the last 12 hours [9].

Adverse effects of Lidocaine include arrhythmias and hypotension. Lidocaine when used as a continuous infusion (usually@ 4-7 mg/kg/hour) it appears to be effective in managing refractory seizures. However, when it is combined with Fosphenytoin) can lead to cardiac toxicity, hence not used commonly as a combination $[1,10]$.

Topiramate: Topiramate is an AED having multi-modal

Dias E, et al. Management of Neonatal Seizures - A Focus on Neuropharmacological Aspects. Pediatr Neonat biol 2018, 3(4): 000131. actions like glutamate receptor inhibition and $\mathrm{Na}+$ channel blockade. Due to its adverse effect profile Topiramate is not routinely a first line monotherapy in neonates with newly diagnosed. It's given $0.5-1 \mathrm{mg} / \mathrm{kg}$ divided in 12 hourly intervals, optimized weekly up to 5 $10 \mathrm{mg} / \mathrm{kg}$. Clinical monitoring of side effects such as weight loss, blurring of vision and eye pain (glaucoma), cognitive side effects, oligohydrosis and metabolic acidosis has to be done in all cases.

Adequate hydration needs to be maintained to decrease the risk of renal stones and this is one of the reasons to limit the use of calcium supplements. It is found to have neuroprotective effects from the injury caused by seizures in neonates.

Topiramate has a higher volume of distribution in comparison to other drugs thus it requires a higher initial and maintenance dose at $3 \mathrm{mg} / \mathrm{kg}$. Research pertaining to determine the efficacy and safety of IV Topiramate in neonates with seizures needs more encouragement $[1,8,9]$.

Lamotrigine (LTG): Lamotrigine is generally tolerated well in children; however, the evidence of generalizing this clinical utility in neonates is limited. In a previous case report, Lamotrigine was used $4.4 \mathrm{mg} / \mathrm{kg} /$ daily single dose as an add-on therapy resulting in sustained control of seizures in neonates $[8,9]$.

Vigabatrin: This drug is used in neonates for refractory seizures mainly for infantile spasms. Routinely used dose of Vigabatrin is $50 \mathrm{mg} / \mathrm{kg} /$ day. As per a study peripheral visual loss is a concerning adverse effect seen in about $15 \%$ of children and hence not routinely used as a treatment option in neonatal seizures $[1,9]$.

Other treatment options which are rarely used in neonates.

Carbamazepine (CBZ): Carbamazepine (CBZ) acts on the voltage-gated $\mathrm{Na}+$ channels thus preventing the repetitive firing of action potentials in depolarized neurons. Due to lack of parenteral formulations and due to the low activity of cytochrome P450 3A4 isoenzyme at birth, the use of CBZ has limitations. However, an "ideal dose in neonates would be a loading dose of $5-20 \mathrm{mg} / \mathrm{kg}$ with maintenance doses of 5-8 mg/kg per dose, administered every 8-12 hours $[8,9]$.

Paraldehyde: It can be used in seizures refractory to first line drugs. A dose of $0.1-0.2 \mathrm{ml} / \mathrm{kg} /$ dose can be given IM or at $0.3 \mathrm{ml} / \mathrm{kg} / \mathrm{dose}$ when mixed with coconut oil in ratio of 3:1 can be used per rectal route. If required then 


\section{Pediatrics \& Neonatal Biology Open Access}

additional doses are given after 30 min and q 4-6 hrly. Potential adverse effects of paraldehyde include pulmonary edema and hemorrhage, hypotension and liver injury.

Use of Paraldehyde is primarily of historical interest as before it had been used for control of refractory seizures. Its exact mechanism of action is not clear. In one trial IV Paraldehyde had been used in treatment of neonatal seizure given as an infusion at the rate of 150 $\mathrm{mg} / \mathrm{kg} /$ hour over 3 hours. Pharmacokinetic data of IV and rectal use of Paraldehyde are limited and thus it's difficult to adjust dosing (as it is used in older children) [1,9].

Felbamate: Felbamate potentiates GAB Anergic action by interacting with strychnine-insensitive glycine recognition site of $\mathrm{N}$-methyl-D-aspartate receptor and thus inhibiting it. Since it is available only as an oral preparation and due to its slow absorption, with oral Felbamate difficult to reach adequate neuroprotective levels in newborns with hypoxic-ischemic encephalopathy [9].

Bumetanide: Bumetanide is a loop diuretic used in term and preterm babies for about 30 years. The usage of Bumetanide for control of neonatal seizure is currently under investigation in NEMO1 (Neonatal seizure using Medication Off-patent) which is a multicenter panEuropean clinical trial for the purpose of developing new treatment strategies. Some evidence suggests that Bumetanide improves GAB Anergic function of Phenobarbitone [8].

Tiagabine: It has been used as an add-on treatment in neonates with refractory partial seizures. NCSE (non convulsive status epilepticus) which is known to occur in about $8 \%$ of patients has to be excluded in children whose seizures and/or mental status deteriorate despite being on treatment. It can be used as an initial daily dose 0.1 $\mathrm{mg} / \mathrm{kg}$ given TID; increased weekly by $0.1 \mathrm{mg} / \mathrm{kg}$ up to a maximum daily dose 0.4 and $0.7 \mathrm{mg} / \mathrm{kg}$ [8]

Dexamethasone: Dexamethasone is not routinely mentioned as a treatment option for neonatal seizures; but it can be seen mentioned in some treatment algorithms. The dose of Dexamethasone as an adjunct in treatment of neonatal meningitis is about $0.6-2.8 \mathrm{mg} / \mathrm{kg}$ IV and given in 4 divided doses over 3-10 consecutive days [9].

Pyridoxine \& Biotin (Metabolic Disorder): Pyridoxine dependent seizures are very exceptional and it is treatable. An optimal dose of $100 \mathrm{mg}$ of pyridoxine is initially given, if ineffective $500 \mathrm{mg}$ should be given intravenously.

A trial of Pyridoxine is kept as a last resort in refractory seizures. The intravenous route is usually the preferred method; but suitable intravenous preparations are not universally available. Hence, intramuscular (IM) route may be administered both sides in either the gluteal region or anterolateral aspect of thigh, with a careful watch for hypotension and apnea. In biotinidase deficiency seizures can be to a certain extent with symptoms like hypotonia, breathlessness will be able to diagnose by measurement of biotinidase activity in serum. This will be treated with Biotin (vitamin H) 5-10 mg/day leads to complete resolution of symptoms [9].

\section{Exchange Transfusion}

This is indicated in life threatening metabolic disorders, trans-placental transfer of maternal drugs, bilirubin encephalopathy etc $[1,19]$ (Figure 1 ).

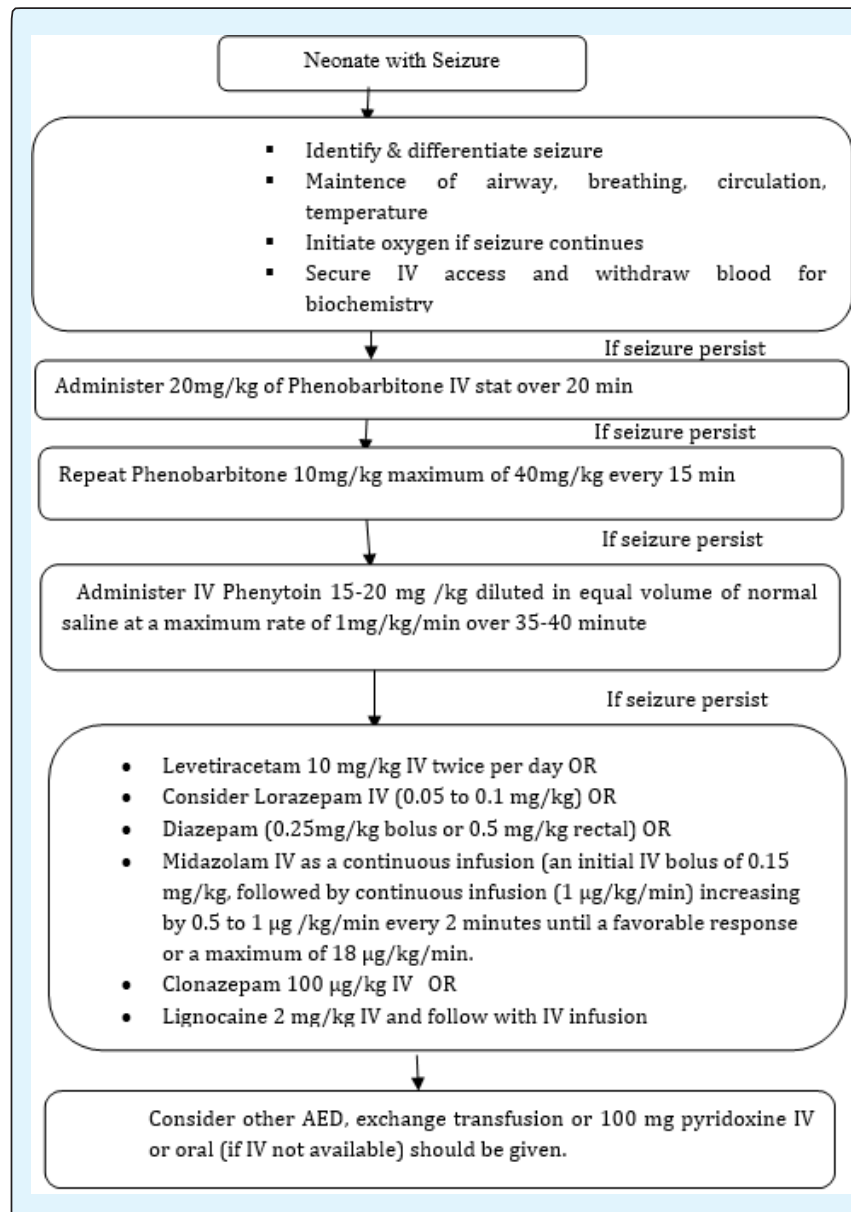

Figure 1: Algorithm for management of neonatal seizures $[16,17,20-24]$. 


\section{Pediatrics \& Neonatal Biology Open Access}

\section{Conclusions}

Phenobarbitone in spite of side effects remains the mainstay of anti -seizure treatment in neonates. Levetiracetam is well tolerated and effective without adjunctive therapy so early use in neonatal seizure, not responding to Phenobarbitone is indicated in recent studies. Levetiracetam is also an alternative of Phenobarbitone in neonatal seizure associated with Hypoxic-ischemic encephalopathy. The management of neonatal seizure is challenging especially where there are congenital anomalies of the CNS and metabolic disorder of newborns presenting as neonatal seizures.

\section{References}

Sankar JM, Agarwal R, Deorari A, Paul VK (2010) Management of neonatal seizures. Indian J Pediatr 77(10): 1129-1135.

Bari AN, Pathan HG, Kokiwar PR (2017) Incidence and outcome of neonatal seizures at a tertiary care hospital. Int J Contemp Pediatr 4(6): 2165-2169.

Nunes ML, Martins MP, Barea BM, Wainberg RC, Costa JC (2008) Neurological outcome of newborns with neonatal seizures: a cohort study in a tertiary university hospital. Arq Neuro-psiquiatr 66(2A): 168174.

Volpe JJ (2008) Neonatal Seizures. Neurology of the newborn, 5th (Edn.), Philadelphia: Saunders. Elsevier pp: 203-244.

(2012) International League Against Epilepsy.

Glass HC (2014) Neonatal seizures: advances in mechanisms and management. Clinic Perinatol 41(1): 177-190.

Expert Committee on Pediatric Epilepsy, Indian Academy of Pediatrics (2009) Guidelines for diagnosis and management of childhood epilepsy. Indian Pediatr 46(8): 681-698.

Kumar A, Gupta A, Talukdar B (2007) Clinico-etiological and EEG profile of neonatal seizures. Indian J Pediatr 74(1): 33-37.

Neubauer D, Soltirovska-Salamon A, Osredkar D, Paro Panjan D (2014) Management of refractory neonatal seizures. Research Reports Neonatology 4: 17-29.

Zeller B, Giebe J (2015) Pharmacologic management of neonatal seizures. Neonatal Netw 34(239): 1-6.

Pacifici MG (2016) Clinical pharmacology of Phenobarbital in neonates: effects, metabolism and pharmacokinetics. Current pediatric reviews 12(1): 48-54.

Tebedge EW (2018) Moving On Up? Phenobarbital vs. LevetiracetamFor First Line Treatment of Neonatal Seizures. UT Health San Antonio pp: 1-18.

Lexicomp Online (2017) Pediatric \& Neonatal Lexi-Drugs. Hudson, Ohio: Lexi-Comp, Inc.

Painter MJ, Scher MS, Stein AD, Armatti S, Wang Z, et al. (1999) Phenobarbital compared with Phenytoin for the treatment of neonatal seizures. N Engl J Med 341(7): 485-489.

Al Baqui SA, Khan MT, Mollah MA, Banerjee M, Rahman MM, et al. (2016) Comparative Efficacy of Phenytoin Versus Lidocaine in the Management of Intractable Seizure in Neonate. J Dhaka Med Coll 25(2): 94-99.

Khanna A, Walcott BP, Kahle KT (2013) Limitations of current GABA agonists in neonatal seizures: toward GABA modulation via the targeting of neuronal $\mathrm{Cl}-$ transport. Front Neurol 4: 78.

Falsaperla R, Vitaliti G, Mauceri L, Romano C, Pavone P, et al. (2017) Levetiracetam in neonatal seizures as firstline treatment: A prospective study. J Pediatr Neurosci 12(1): 24-28.

Mruk AL, Garlitz KL, Leung NR (2015) Levetiracetam in neonatal seizures: a review. J Pediatr Pharmacol Ther 20(2): 76-89.

Kliegman RM, Stanton BMD, Joseph G, Schor NF (2018) Nelson Textbook of Pediatrics, 2-Volume Set, 20th (Edn.), Elsevier.

$\mathrm{Au}$ CC, Branco RG, Tasker RC (2017) Management protocols for status epilepticus in the pediatric emergency room: systematic review article. J Pediatr (Rio J) 93(Suppl 1): 84-94.

Queensland Health (2018) Maternity and Neonatal Clinical Guidelines. Queensland Clinical Guidelines.

Tooley WH (2003) Intensive care nursery house staff manual. The Regents of the University of California. California. UCSF Children's Hospital pp: 140-143.

Spagnoli C, Pavlidis E, Pisani F (2013) Neonatal seizures therapy: we are still looking for the efficacious drug. Ital J Pediatr 39: 37.

Roy MK, Das D (2013) Indian guidelines on epilepsy. IAP expert committee guidelines pp: 528-532.

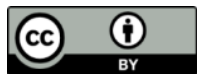

